Capítulo 13

\title{
Contribuições dos Mattelart para pensar os processos midiáticos na perspectiva das inter-relações dos sujeitos com as mídias
}

DOI: https://doi.org/10.16921/ciespal.23.33

Jiani Bonin

Universidade do Vale do Rio dos Sinos - Unisinos

\section{Introdução}

A obra de Armand e Michéle Mattelart é reconhecida como fundamental para a construção do pensamento crítico e da investigação na América Latina. Marcada por um constante questionamento e reflexão de seus pressupostos e por forte compromisso ético e político, continua nos oferecendo elementos férteis para pensar os processos comunicacionais/midiáticos contemporâneos. ${ }^{1}$

Entre estas contribuições, encontramos subsídios relevantes para problematizar, de modo crítico e aprofundado, os processos comunicacionais/midiáticos na perspectiva dos seus usos e apropriações sociais. São particularmente instigantes neste sentido as proposições desenvolvidas nas obras de reflexão epistemológica sobre o campo teórico da comunicação, entre as quais destaco aquelas publicadas em Pensar sobre los medios (Mattelart \&Mattelart, 1987). Encontramos aí, entre outros elementos, uma reflexão aprofundada de teorias que, na trajetória do campo da comunicação, fundamentaram as perspectivas

1 Uma análise aprofundada desta compreensão pode ser encontrada em Maldonado (2015). 
de compreensão do âmbito da recepção e do consumo. Também destaco as contribuições para pensar a problemática do cibercontrole, com tratamento apurado nas obras Un mundo vigilado (Mattelart, 2009) e De Orwell al cibercontrole (Mattelart \& Vitalis, 2015), como fundamentais para pensar questões vinculadas ao poder nos processos comunicacionais digitais e seus usos e apropriações sociais. Neste texto, busco justamente recuperar estes aportes para a pesquisa que focaliza as inter-relações dos sujeitos com as mídias nestas duas linhas de investigação.

\section{A reflexão epistêmica das teorias e suas concepções da recepção}

No livro Pensar sobre los medios, os Mattelart se dedicam a uma reflexão epistêmica sobre o campo teórico da comunicação, examinando particularmente sua constituição na França. Coerentes com a posição epistemológica da necessidade de recuperar a genealogia dos conceitos e das palavras, problematizam os termos recepção e consumo por se erigirem e se fundamentarem em perspectivas funcionalistas que dissociam os polos da emissão e da recepção. Fazem, assim, uma crítica ao reducionismo que operam ao considerar a recepção um fenômeno destacado do processo comunicacional. Além disso, problematizam proposições que sustentam estas concepções do receptor: a psicologia behaviorista, que reduz a compreensão do comportamento humano aos processos de estímulo e resposta e a noção de massa, assentada em propostas de cariz antipopular e conservador que convergem nas ideias de homogeneização social promovida pelas novas condições instauradas pela sociedade moderna e da ação massificante dos meios de comunicação de massa. Nesta via, a problemática da comunicação é reduzida à mera transmissão e recepção de mensagens. São omitidos os vínculos dos processos comunicacionais com as estruturas sociais e com os poderes ligados ao campo econômico e político. Visualizam aí um receptor mutilado e funcionalizado: despojado de sua 
complexidade, desvinculado dos contextos múltiplos em que vive, despido de história, destituído da sua condição de produtor de sentidos, meramente programado, influenciado, persuadido.

Os Mattelart refletem, ainda, sobre os condicionamentos destas propostas funcionalistas: seu caráter administrativo, os vínculos das pesquisas a interesses comerciais, estatais e geopolíticos estadunidenses - que marcam suas condições de produção científica. Deslindam como estas perspectivas estiveram na base das políticas intervencionistas estadunidenses em vários países da América Latina, nos modelos teóricos de difusão de inovações que serviram para fundamentar programas de modernização de culturas consideradas atrasadas para inseri-las na ordem do consumo do e do estilo de vida americano. (Mattelart, 2014; Mattelart \& Mattelart, 1997).

Neste itinerário reflexivo sobre as teorias da comunicação, os pesquisadores refletem que as propostas críticas desenvolvidas por Adorno e Horkheimer vinculadas ao conceito de Indústria Cultural e o estruturalismo de Althusser também operaram com o postulado implícito de onipotência da mídia. Por um lado, elas contemplam a problemática do poder, dos vínculos das mídias com o sistema e com a dominação capitalista, da produção industrial da cultura e das consequências deste processo. Por outro, reduzem a complexidade dos processos midiáticos dadas as concepções monolíticas sobre os meios e seu poder manipulatório. Desde estas compreensões, desenha-se teoricamente um receptor inserido e constituído dentro das tramas do sistema capitalista e manipulado pela malha sistêmica da Indústria Cultural e dos Aparelhos ideológicos de estado. Um poder, agora reconhecido, mas sem contradições, assujeita os indivíduos sem abrir brechas para possibilidades de resistência e, ou contestação.

Se na França a pesquisa em comunicação é dominada pelas vertentes estruturalistas por longo tempo, os Mattelart recuperam criticamente o legado das perspectivas críticas dos estudos culturais ingleses como contribuições para a problemática que examinamos, o questionamento da passividade dos receptores e o desbloqueio das cegueiras das teorias 
anteriormente examinadas em relação às práticas e à atividade dos sujeitos (Mattelart \& Neveu, 2004; Mattelart \& Mattelart, 1987).

O exame dos Mattelart sobre a vertente crítica dos Estudos culturais reconhece seu aporte para pensar os processos comunicacionais em suas vinculações com o campo cultural e o poder, as possibilidades abertas pela incorporação do conceito de hegemonia às pesquisas para complexificar a compreensão das instâncias da produção, dos produtos, da recepção e de suas inter-relações. Na obra Introducción a los estudios culturales, Mattelart \& Neveu (2004) consideram também, entre outros aspectos, a contribuição de Hall para o reconhecimento da defasagem entre as gramáticas midiáticas da produção das mensagens e as referências culturais dos sujeitos; da natureza discursiva dos produtos midiáticos e de suas vinculações com interesses e estratégias do sistema produtivo que o engendram e com modelos cognitivos operantes nos contextos sociais em que se inserem. No âmbito da recepção, apontam que a noção de decodificação convida a considerar a cultura como dimensão imbricada nos processos de recepção e as possibilidades diversas de leitura, não limitadas à reprodução dos sentidos preferenciais ofertados nos produtos midiáticos.

Estas propostas abrem possibilidades para repensar o campo midiático como lócus de relações e de práticas sociais produtoras de sentidos. O poder simbólico das mídias pode agora ser relido em chave mais complexa, que permite dar entrada a conflitos, ambiguidades, ambivalências e contradições que aí se afiguram. Abrem-se vias para considerar os trânsitos entre os produtos midiáticos e as culturas, as negociações, resistências e contestações que podem se constituir nessa inter-relação. Os sujeitos na recepção são situados no contexto social e cultural, dimensões estas constituintes de suas práticas de sentido e das relações estabelecidas com as mídias. São contempladas as possibilidades de resistência à dominação simbólica a partir de repertórios, estilos e modos de fazer das classes populares.

Os Mattelart reconhecem ainda o aporte das proposições certeaunianas voltadas a pensar os desvios táticos operados pela criatividade 
dos sujeitos desde seu lugar subordinado nas estruturas sociais e de produção cultural, a partir das maneiras de usar e de se apropriar dos produtos culturais. Sem negar o poder, as concepções certeaunianas ajudam a pensar as possibilidades de vigência de restos e estilos culturais que permitem operar desvios e resistir taticamente no cotidiano, nas artes de fazer, nas apropriações dos produtos culturais. ${ }^{2}$ Além disso, a problemática das identidades culturais é examinada em detalhes nas pesquisas, permitindo considerar, além das classes sociais, as culturas geracionais, de género, de sexualidade e étnicas. São examinados os modos como são constituídas as identidades das pessoas e como se inter-relacionam com as mídias.

A recusa das fronteiras disciplinares é outro elemento considerado produtivo no legado dos estudos culturais; o trânsito entre propostas advindas de campos de saber diversos permitiu complexificar as problematizações teóricas dos processos comunicacionais e impulsionou a experimentação de métodos. No âmbito da recepção, combinações metodológicas renovadas, aliando métodos etnográficos, história oral, entrevistas de naturezas diversas, e outros procedimentos metódicos que permitiram aos investigadores vivenciar e observar os processos comunicacionais no seu acontecer cotidiano, reconstruir trajetos históricos de vida comunicacional e midiática dos sujeitos e colher relatos expressivos das significações produzidas.

A combinação singular entre pesquisa e engajamento social é reconhecida como um elemento fértil das duas primeiras gerações de pesquisadores desta vertente. $\mathrm{O}$ trabalho intelectual destes pesquisadores, fecundado pelo compromisso com a mudança de uma ordem social que consideravam injusta e à qual desejavam mudar, não derivou para a ortodoxia e alimentou uma "forte sensibilidade aos desafios sociais semeados pelo efeito-gueto do mundo acadêmico" (Mattelart \&Neveu, 2004, p.92).

2 Mas eles apontam também como as simplificações e vulgarizações da proposta certeauniana levam a derivas e à celebração das resistências, particularmente a partir da década de 80, como discuto na sequência deste texto. Esta problematização é tratada em Mattelart (1994), Mattelart \& Neveu (2004), Mattelart \& Mattelart $(1987,1997)$. 
Os Mattelart reconhecem a renovação conceitual aberta por estas proposições que marcam "o retorno do sujeito", abrindo caminho para pensar os processos de recepção como parte de um conjunto de práticas culturais, como instância indissociável dos processos midiáticos e do contexto sociocultural mais amplo em que estão inseridos.

Por outro lado, a acuidade do exame epistemológico desta vertente teórica leva os Mattelart a dimensionar, mesmo no legado dos pesquisadores críticos mais importantes desta linha, insuficiências, destacando-se aquelas vinculadas ao déficit na problematização das dimensões histórica e econômica. A carência de perspectiva histórica acarretou a negligência da duração longa no cultural em muitas pesquisas. A deficiência no tratamento da dimensão econômico política dificultou pensar aquilo que nos processos midiáticos remete ao funcionamento das indústrias culturais, a suas lógicas, ao campo da produção enquanto espaço interdependente e competitivo. Os pesquisadores assinalam também derivas investigativas no sentido de superestimar as resistências das culturas populares.

A ampla popularização e disseminação que esta vertente ganha em vários países é acompanhada de ambivalências, derivas e simplificações perigosas. A evolução da virada etnográfica rumo à ênfase no dimensionamento do consumo como ativo e das leituras desviantes leva as pesquisas a minimizar o papel estratégico que os meios ocupam na reprodução das relações sociais, os determinantes econômicos e políticos configuradores dos dispositivos comunicacionais (Mattelart \& Mattelart, 1987; Mattelart \& Neveu, 2004).

O tratamento da gênese das relações internacionais de força em matéria de produtos culturais também é outro ponto descuidado, a problemática da "interpenetração das culturas, das economias e das sociedades a partir do reconhecimento da troca desigual entre essas culturas, das lógicas de exclusão inerentes ao processo de integração mundial dos sistemas técnicos e econômicos" (Mattelart \& Neveu, 2004, p.126).

Essas contradições são constatadas também em pesquisas de recepção desenvolvidas na América Latina, que confinam as práticas de 
consumo à resistência, reproduzindo modelos e referências sem problematização. Os autores refletem que a noção de mediações, que junto com a de hegemonia foi fecunda para romper com o estruturalismo, vai sendo reduzida ao virar moda acadêmica. Ao realizar um balanço sobre os fatores que contribuíram para o enfraquecimento do sentido político dos estudos culturais na América Latina, apontam os seguintes:

[...] a ausência de perspectiva histórica, que explica notadamente a adesão precoce e acrítica à noção de globalização; o desconhecimento das análises formuladas pela economia política das indústrias culturais e das indústrias informacionais; a hesitação em se interrogar sobre as lógicas dos sistemas técnicos; a crescente defasagem diante das novas dinâmicas do movimento social; e por fim, mas não último, a carência de problematização do novo estatuto do saber e dos intelectuais no capitalismo contemporâneo caracterizado pelo duplo movimento de subsunção do trabalho e do consumo a partir da expansão em todos os setores da vida, das tecnologias de comunicação e de informação (Mattelart \& Neveu, 2004, p.156).

Estas perspectivas vão se tornando mais ambivalentes no contexto de instalação (iniciada nos anos 70) do regime pós fordista caracterizado pela flexibilidade e no qual a comunicação ocupará um lugar central nas estratégias de reestruturação de nossas sociedades, quando as tecnologias eletrônicas vão se instaurar como um dispositivo central de reconversão dos países industrializados.

A expansão das novas tecnologias de comunicação digital vem acompanhada da instauração de um novo modo gerencial de governo da sociedade, problemática a que Mattelart passa a se dedicar, como examino na sequência.

\section{O cibercontrole como dimensão chave para entender o poder nos processos comunicacionais digitais}

Para iniciar, é importante considerar que os aportes investigativos de Mattelart para pensar a problemática do cibercontrole são 
construídos a partir de um procedimento genealógico, que lança luz sobre o processo histórico que leva à constituição do cibercontrole. Essa mirada, fortalecida pelo tratamento da dimensão econômico política, abre possibilidades férteis para compreender de modo mais efetivo o processo de constituição desta renovada forma de controle social e apreender seu sentido político, suas especificidades e consequências sociais.

A genealogia dos usos e funções das tecnologias de controle social permite vê-las como dispositivos tecnopolíticos historicamente desenvolvidos, testados, experimentados e renovados, com o objetivo de controle. A investigação sobre os contornos específicos que ganha o desenvolvimento das técnicas de elaboração de perfis das pessoas e o exame de sua articulação com interesses estatais, geopolíticos e mercadológicos é particularmente interessante para nutrir quadros de compreensão das inter-relações dos sujeitos com as mídias digitais. Nesta perspectiva, são examinadas suas transformações até a expansão global, impulsionada pela razão mercantil da hegemonia neoliberal e pelo avanço desmedido das estratégias de segurança nacional, aliados às tecnologias digitais. ${ }^{3}$

O olhar dos autores permite dimensionar como os progressos políticos e relativos a direitos vêm acompanhados de formas de controle que limitam seus efeitos, e como a seguridade prescreve limites à liberdade. Mostra que as tensões entre liberdade e controle se complexificam historicamente e conhecem derivas, que se intensificam nos períodos de crise econômica, revolução política e de guerras, quando se faz ver de modo mais pronunciado o uso de meios de controle existentes bem como a invenção de tecnologias de vigilância mais eficazes.

Vale restituir, aqui, os contornos mais salientes deste processo no qual se desenvolve uma renovada forma de governo, o cibercontrole. Sua reconstrução tem como ponto de partida o contexto da Revolução

3 Esta problemática é tratada de modo ampliado e frutífero em Un mundo vigilado (Mattelart, 2009) e em De Orwell al cibercontrol (Mattelart \& Vitalis, 2015). Nesta última obra, os pesquisadores procuram examinar a problemática do cibercontrole tomando como foco o perfilado a partir da realidade local do Estado francês, explorando seus entrelaçamentos com dimensões globais do fenômeno. 
Industrial, mais especificamente a década de 1850, momento que marca um ponto de inflexão a partir do qual toma forma uma economia ancorada na divisão internacional do trabalho. Neste cenário, o mercado torna-se o eixo de um novo ordenamento das relações sociais, demandando liberdade de deslocamento de pessoas e mercadorias, fundamental para a realização da nova ordem econômica. Paradoxalmente, vão sendo criados e aperfeiçoados, pelos Estados e pela polícia, mecanismos de controle da circulação de nômades, profissionais ambulantes, sem teto e imigrantes, demonstrando a obsessão dos poderes pelas populações marginalizadas. A estatística é posta a serviço dos controles policiais, tornando-se uma ferramenta de regulação social, inaugurando a matematização da gestão das massas.

Neste período, a medição, o controle e a regulação do tempo passam a ordenar a experiência social. As fábricas tornam-se um lócus chave de experimentação e de aperfeiçoamento de dispositivos de controle destinados ao seguimento dos trabalhadores e à cronometragem de seus gestos para desenvolver processos de maximização dos rendimentos dos fluxos de trabalho, na linha do taylorismo, sustentados também por estudos voltados à eficiência e à psicologia industriais.

Logo vão se consolidar os processos de taylorização do consumo, alimentados pela comunicação de massas e pela indústria da publicidade em desenvolvimento. A partir da década de 40, o consumo vai se convertendo em campo de experimentação de técnicas de sondagem para controle dos comportamentos dos consumidores, com vistas a conhecer e atuar sobre suas necessidades. Estas experimentações antecedem e preparam o desenvolvimento das estratégias contemporâneas de mineração de dados desenvolvidas no ambiente digital para produção de perfis dos consumidores.

Depois da Segunda Guerra Mundial, no contexto europeu, o Estado do Bem-Estar Social cria medidas de proteção às populações empobrecidas e instaura formas de seguimento das populações assistidas. Desenvolve-se neste âmbito um sistema burocrático de administração e de gestão de dados das populações. Expandem-se os bancos de dados 
públicos, assim como os privados, o que possibilita a ampliação de formas de vigilância e as possibilidades de controle social. Técnicas estatísticas vão ser colocadas a serviço destas formas de seguimento e de regulação social.

No Pós-Guerra, num cenário de Guerra Fria, a segurança nacional é colocada em primeiro plano no âmbito das políticas dos Estados, particularmente naqueles envolvidos no conflito. Os Estados Unidos desenvolvem um complexo militar-industrial, onde serão posteriormente inventados os sistemas teleinformáticos que permitirão o desenvolvimento dos dispositivos futuros de vigilância massiva. Desde a década de 40 dedicam-se a uma economia de guerra permanente, na qual as tecnologias de informação e de comunicação tem um papel chave. Satélites, sistemas informáticos de espionagem, tecnologias de geolocalização, drones e armas não letais formam parte dos dispositivos desenvolvidos, testados e aperfeiçoados neste âmbito.

A partir da década de 70 temos o declínio do Estado providência, acompanhado de crises de governabilidade da democracia e do modelo de crescimento econômico, que abre caminho para o neoliberalismo e para suas políticas de desregulamentação selvagem. As tecnologias de informação são vistas pelas sociedades industriais como elemento central para a saída da crise. A partir daí, elas vão se disseminar socialmente, abrindo caminho para uma revolução informática do controle.

No começo do século XXI, a segurança nacional volta a ganhar relevo nas estratégias dos Estados ocidentais, agora com o pretexto de combate ao terrorismo. Surge a figura do Estado vigilante. A partir dos atentados de 11 de setembro de 2001, o governo estadunidense passa a reforçar seu arsenal securitário, civil e militar. Deflagra-se uma mobilização generalizada dos Estados ocidentais para a seguridade, que se reforça a partir dos atendados de 11 de março de 2004 em Madrid, de 7 de julho de 2005 em Londres e de 7 de janeiro de 2017, em Paris. Este avanço das dinâmicas securitárias repercute nos processos de comunicação e de circulação de pessoas, mensagens e bens. A guerra contra o terrorismo se internacionaliza e se torna um elemento comum 
das políticas, doutrinas e estratégias de segurança em várias partes do mundo, com os países ocidentais em primeiro plano. Fortalecem-se as sinergias interagências e intersetores. As doutrinas de guerra passam a se orientar para o campo da informação, com o objetivo de atuar na capacidade de compreensão e de ação do inimigo. Para os Estados Unidos, tornar operativa essa guerra significará reestruturar os mecanismos de coleta e de disseminação da informação em nível mundial, colocar em rede as agências de inteligência e amplificar sua capacidade de análise.

Neste contexto, a interconexão de bancos de dados policiais e administrativos se acelera, impulsionada pela preocupação das autoridades públicas de identificar focos potenciais de comportamentos violentos ou desviados. As medidas progressivamente implementadas pelos Estados estabelecem as bases de uma estrutura renovada de controle, assentada no aumento de bancos de dados e de suas interconexões, na melhoria de identificação das pessoas (especialmente através da biometria) e na experimentação de métodos automáticos de classificação e de detecção.

Historicamente, a construção de bancos de dados e de perfis havia sido realizada pelos Estados. No período entre guerras, o desenvolvimento da indústria da publicidade e do marketing moderno impulsiona o aperfeiçoamento de métodos de observação e de análise de comportamento dos consumidores para o estabelecimento de perfis voltados ao conhecimento dos públicos, junto ao incremento das novas tecnologias.

Com o avanço da digitalização, vemos consolidarem-se monopólios fundados na exploração mercantil de dados pessoais, em geral assentados no oferecimento de serviços públicos gratuitos e na participação das pessoas em redes sociais. $\mathrm{O}$ aumento da capacidade de memória dos suportes digitais, assim como a desterritorialização dos processamentos, a automatização da coleta, o uso de algoritmos e o entrecruzamento e a difusão de dados potencializam a exploração de dados das pessoas.

Todo esse processo leva à constituição de uma renovada forma de governo que se distingue da sociedade disciplinar, atuante por mais de três séculos na perspectiva de Foucault, e instaurada a partir do 
Renascimento conforme Elias, caracterizada por inscrever a normalização social no interior do indivíduo. A sociedade disciplinar é marcada pela visibilidade de sua arquitetura e de seus dispositivos disciplinares, que induz ao controle do comportamento. O sujeito participa de sua normalização através de auto restrição e autocontrole.

Em contrapartida, a sociedade do cibercontrole assenta-se na invisibilidade e na automatização das tecnologias. O indivíduo é aparentemente livre, mas está permanentemente vigiado. Ele é objeto da informação e, em caso de comportamento desviante, são tomadas decisões que são imediatamente aplicadas. O sistema de vigilância contemporâneo é marcado também pela fluidez, pela mobilidade e pela conectividade, características impulsionadas pelas tecnologias e redes de comunicação e de informação. Este entorno digital facilita a comunicação, ao mesmo tempo em que se constitui como um cenário de controle permanente. Os conteúdos podem ser transmitidos instantaneamente, armazenados e processados em qualquer lugar do planeta. Além disso, os dispositivos de controle se encontram hoje desterritorializados.

Nestes processos, emerge uma nova forma de governo fundada em predição e, sobretudo, em prevenção e modulação de comportamentos mediante a aplicação de algoritmos a quantidades massivas de dados para elaboração de perfis e estruturação do campo de ações possíveis dos indivíduos. Seus usos incluem redução de riscos e intervenção, pela detecção automática de comportamentos anormais antes que se produzam os atos delitivos e previsão de necessidades e desejos das pessoas a partir do trato de seus dados para performar o consumo. Este viés antecipador e seu imediatismo são traços distintivos em relação a outras formas de controle. Vale considerar, como bem refletem os autores, que embora se instaure uma nova forma de governo, isso não significa que o regime disciplinar não continue atuando e que novas tecnologias de informatização e comunicação não possam, inclusive, prolongá-lo.

A dimensão legal também é objeto de reflexão. Neste âmbito, são examinados por Mattelart \& Vitalis (2015) os marcos desenvolvidos pelo Estado francês em relação às tendências no contexto da União Europeia 
e dos Estados Unidos. Os autores refletem sobre a dessincronização cada vez mais manifesta entre os ritmos dos processos de informatização e os esforços jurídicos para proteção de seus abusos e sobre as fortes distinções entre o modelo regulatório estadunidense e europeu em termos de proteção da privacidade das pessoas. Ainda assim, consideram sua importância simbólica, pois formalizam e precisam os direitos dos cidadãos sobre suas informações numa sociedade democrática. Eles apontam ainda e sobre as fortes distinções entre o modelo regulatório estadunidense e europeu em termos de proteção da privacidade das pessoas. Refletem que a regulação deveria intervir desde a concepção destes automatismos, direção colocada pelo enfoque privacy by design, que propõe atuar desde a concepção de materiais, programas e arquiteturas de modo a garantir o respeito à vida privada.

No tratamento da problemática do cibercontrole, os pesquisadores não deixam de considerar as contradições, fissuras e possibilidades de resistência dos sujeitos que usam e se apropriam das tecnologias. São reconhecidas as possibilidades abertas em termos de geração e de compartilhamento de conhecimentos e de informações, de acesso às condições de produção de conteúdos, de estabelecimento de vínculos estendidos, de experimentações diversas, de constituição de novos movimentos e ativismos, de reflexão e criação estética. No campo dos usos, consideram as possibilidades das pessoas também acederem às ferramentas de controle utilizadas pelos controladores e converterem-se em vigilantes. Neste sentido, apontam várias formas de uso de tecnologias a serviço da vigilância cidadã para denunciar os métodos e as formas de abuso dos vigilantes, embora questionem também suas ambiguidades e possibilidades efetivas de subversão do cibercontrole. Observam que pessoas com maior competência técnica tem mais condições de proteger-se do cibercontrole, a partir do uso de ferramentas específicas de proteção. Além disso, as pessoas podem também optar por práticas de desconexão e, ou por não fazer uso de ambientes cujas práticas abusivas vão sendo conhecidas. 
Tentei neste texto resgatar algumas das relevantes contribuições de obras cruciais dos Mattelart (e colaboradores) para pensar a problemática dos usos e apropriações das mídias. Ao finalizar este itinerário, destaco que o exame epistêmico dos pesquisadores em relação às formulações teóricas no campo da comunicação e seu modo de conceber a recepção mostra as carências e limitações de abordagens que: seccionam esta dimensão da totalidade do processo comunicacional, expulsando de suas formulações as inter-relações de conjunto do seu entendimento; reduzem a problemática da comunicação à transmissão de mensagens; omitem a dimensão semiótica destes processos; negligenciam sua dimensão econômico política e os interesses que moldam os processos de produção simbólica; reduzem e objetificam os sujeitos, concebendo-os como seres passivos e totalmente manipuláveis diante dos poderes midiáticos; desconsideram a complexidade destes sujeitos e a multidimensionalidade dos contextos constitutivos de suas culturas e das suas produções de sentido. Ao mesmo tempo, reforça a necessidade de pensar a problemática das inter-relações dos sujeitos com as mídias digitais em bases complexas e que considerem a complexidade e a multidimensionalidade constitutivas dos processos comunicacionais/midiáticos e dos sujeitos em comunicação.

Considero, também, que as perspectivas desenvolvidas para a compreensão do cibercontrole são fundamentais para entender sua gênese, desenvolvimento, modos de atuação e os interesses Estatais, mercadológicos e geopolíticos que fundamentam sua constituição. Oferecem uma contribuição crucial para problematizar como os lastros econômico-políticos das tecnologias digitais e as renovadas formas de poder e de controle que inauguram atravessam os usos e apropriações sociais das tecnologias. Também nos desafiam como pesquisadores no sentido de problematizar o avanço de suas lógicas no contexto contemporâneo.

Isso é particularmente necessário no cenário atual da crise instaurada pela expansão da COVID-19, que vem beneficiando exponencialmente as corporações que têm seus modelos de negócio baseados na 
exploração de dados das pessoas. Vários Estados passaram a aplicar estratégias de vigilância digital com o intuito de controlar a disseminação da doença. Coreia do Sul, Singapura, China e também Taiwan e Hong Kong desenvolveram sistemas de cibervigilância a partir de aplicativos para smartphones com a finalidade de realizar seguimento digital de cidadãos com a doença ou que estiveram presentes em zonas de contágio. Este modelo, baseado no uso massivo de dados e associado a sistemas de videoproteção, vem sendo adotado também em países como Alemanha, Reino Unido, França e Espanha. Dados de provedores de telefonia móvel e de internet têm sido utilizados por Estados para prevenir a expansão da doença e monitorar os infectados. Os gigantes da internet Google e Apple também se associaram ao propósito de realizar rastreio dos infectados pela doença e vem desenvolvendo tecnologias para alertar as pessoas quando elas chegarem perto de alguém que teve teste positivo para o novo coronavírus. Além disso, acompanhamos o aprofundamento dos usos das tecnologias digitais nos mais variados âmbitos sociais - como nos domínios do teletrabalho, da teleducação e da telemedicina. Neste processo, aprofundam-se os riscos diante da possibilidade de que as medidas de exceção adotadas possam permanecer no futuro, particularmente as que se vinculam à cibervigilância e ao biocontrole (Ramonet, 2020).

\section{Referências}

Maldonado, E. (2015). Epistemología de la comunicación. Análisis de la vertiente Mattelart en América Latina. Quito: CIESPAL.

Mattelart, A. (1994). Comunicação mundo: história das ideias e das estratégias. Petrópolis: Vozes. . (2009). Un mundo vigilado. Barcelona: Paidós. . (2014). Por una mirada-mundo: Conversaciones con Michele Sénécal. Barcelona: Gedisa. 
Mattelart, A. \& Neveu, E, (2004). Introducción a los estudios culturales, Barcelona: Paidós.

Mattelart, A. \& Mattelart, M. (1987). Pensar sobre los medios: Comunicación y crítica social. Madrid: FUNDESCO.

. (1997). Historia de las teorías de la comunicación. Barcelona: Paidós.

Mattelart, A.; Vitalis, A. (2015). De Orwell al cibercontrol. Barcelona: Gedisa.

Ramonet, I. (2020). Ante lo desconocido la pandemia y el sistema-mundo. Le Monde Diplomatique, 30 de abril. Recuperado de https://mondiplo.com/ la-pandemia-y-el-sistema-mundo. 